\title{
PENSAMENTO CRÍTICO E CRIATIVIDADE NA EDUCAÇÃO: COMPLEMENTARIDADE E NECESSIDADE FRENTE À COVID-19
}

\author{
Themys de Cássia Moura de Carvalho ${ }^{1}$ \\ Leandro S. Almeida ${ }^{2}$
}

\section{RESUMO}

O pensamento crítico e a criatividade compartilham inúmeras características, como ferramentas educacionais muito úteis em uma sociedade como a atual, na qual o mero conhecimento convencional do currículo escolar não é mais suficiente para integrar-se a uma variedade de campos profissionais e setores sociais. Nesse sentido, é necessário e urgente treinar os alunos para desenvolver um espírito questionador, crítico e investigativo, ao mesmo tempo que comprometido e solidário com a sustentabilidade global. Além disso, está a recente crise do Covid-19, que teve um impacto devastador na educação, o que trouxe para o primeiro plano a necessidade de promover a autorregulação dos alunos na sua aprendizagem em casa.

Palavras-chave: Desenvolvimento de criatividade; Desenvolvimento de pensamento crítico; Competências transversais; Ensino a distância; Autorregulação da aprendizagem.

\section{CRITICAL THINKING AND CREATIVITY IN EDUCATION: COMPLEMENTARITY AND NEED IN FRONT OF COVID-19}

\begin{abstract}
Critical thinking and creativity share numerous characteristics, since they are educational tools that are very useful in a society like today, in which mere conventional knowledge of the school curriculum is no longer enough to integrate into a variety of professional fields and social sectors. In this sense, it is necessary and urgent to train students to develop an inquiring, critical and investigative spirit, at the same time that they are committed and supportive of global sustainability. Added to this is the recent crisis of Covid-19, which has had a devastating impact on education, making face-to-face teaching impossible in most schools on the planet, which has brought to the fore the need to promote the selfregulation of students in their learning from home.
\end{abstract}

Keywords: Creativity development; Critical thinking development; Transferable skills; Distance teaching; Self-regulation of learning.

\section{PENSAMIENTO CRÍTICO Y CREATIVIDAD EN EDUCACIÓN: COMPLEMENTARIEDAD Y NECESIDAD FRENTE A LA COVID-19}

\footnotetext{
${ }^{1}$ Doutora em Ciências da Educação (com Especialidade em Psicologia da Educação) pela Universidade do Minho, Portugal. Funcionário publica da Secretaria da Educação do Estado do Maranhão - Brasil. Professora na Maestria em Processos Psicológicos em Educación na Universidad de Nariño - Colômbia. Investiga os temas da Cognição e aprendizagem. E-mail: <themyscarvalho@hotmail.es>. ORCID ID.: https://orcid.org/0000-0002-7483-7722.

2 Doutor em Psicologia (Psicologia da Educação) pela Universidade do Porto, Portugal. Professor Catedrático de Psicologia da Educação na Universidade do Minho (Campus de Gualtar, Braga-Portugal). Investiga os temas da cognição e aprendizagem. Coordenador da especialidade de Psicologia da Educação no Doutoramento em Ciências da Educação da Universidade do Minho, sendo membro do Centro de Investigação em Educação (CIEdUM). E-mail: <leandro@ie.uminho.pt>. ORCID ID.: http://orcid.org/0000-0002-0651-7014.
} 


\section{RESUMEN}

El pensamiento crítico y la creatividad comparten numerosas características, como herramientas educativas de gran utilidad en una sociedad como la actual, en la que ya no es suficiente el mero conocimiento convencional del currículo escolar para integrarse en una variedad de ámbitos profesionales y sectores sociales. En este sentido, es necesario y urgente formar al alumnado para desarrollar un espíritu indagador, crítico e investigador, al mismo tiempo que comprometido y solidario con la sostenibilidad global. A ello se une la reciente crisis de la Covid-19, que ha tenido un impacto devastador en la educación, imposibilitando la enseñanza presencial en la mayoría de las escuelas del planeta, lo que ha traído al primer plano la necesidad de promover la autorregulación de los alumnos en su aprendizaje desde casa.

Palabras clave: Desarrollo de la creatividad; Desarrollo del pensamiento crítico; Competencias transversales; Educación a distancia; Autorregulación del aprendizaje.

\section{INTRODUÇÃO}

Não há dúvida de que a sociedade atual está inserida em um processo de profundas e contínuas mudanças para as quais é necessário preparar as gerações futuras. De acordo com a Organização para Cooperação e Desenvolvimento Econômico (OCDE, 2018), as escolas enfrentam demandas crescentes para preparar os jovens para empregos que ainda não foram criados, lidar com tecnologias que ainda não foram inventadas e resolver problemas sociais que ainda não sabemos equacionar. Segundo o Fórum Econômico Mundial (2016), 90\% das pessoas terão que continuar aprendendo durante a vida profissional e mais de $60 \%$ dos alunos que frequentam a escola agora acabarão trabalhando em empregos que ainda não existem.

Nesse contexto de globalização, avanços tecnológicos e explosão do conhecimento científico, os alunos precisarão desenvolver e aplicar habilidades cognitivas e competências emocionais em seu percurso formativo e em seu futuro profissional, como autoeficácia, gestão de emoções, cooperação, autorregulação, pensamento crítico e criatividade (FLEITH; BRAGA, 2019). Isso implica criar condições adequadas no ambiente escolar que nem sempre são fáceis de implementar, uma vez que as reformas regulatórias geralmente não chegam à sala de aula e os planos de estudo não vão além do papel (SAIZ, 2018). Dessa maneira, o ensino magistral permanece bastante frequente e incólume em nossas salas de aula (LAITON POVEDA, 2019).

Ao exposto, acrescenta-se que o atual contexto profissional oferece menos empregos e salários mais baixos do que no passado. Esta situação pode ser desanimadora para muitos estudantes. No entanto, apesar de haver mais demanda e menos oferta de 
empregos, os jovens mais esforçados e com melhor preparação sempre encontrarão mais possibilidades de inserção e promoção profissional (SAIZ, 2018). Por outro lado, a missão da escola não é tanto ensinar ao aluno uma infinidade de conhecimentos de campos especializados, mas promover sua autonomia intelectual e que aprenda a aprender. Nesse sentido, Saiz e Rivas (2020) destacam que não é possível crescer, progredir ou alcançar certos níveis de bem-estar e sucesso acadêmico sem esse conhecimento interior de si mesmo, ou seja, sem competências cognitivas desenvolvidas e sem estratégias comportamentais eficazes para a tomada de decisão e solução de problemas. Para isso, habilidades transversais como criatividade e pensamento crítico, que podem estar presentes em uma variedade de disciplinas e idades, contribuem para formar um pensamento de ordem superior (LIPMAN, 1998).

$\mathrm{Na}$ psicologia cognitiva usualmente diferenciam-se as competências funcionais associadas à atenção, perceção e memória, e as competências de planeamento ou metacognitivas. Estas últimas orientam ou moniorizam as primeiras no sentido da sua operacionalização e maior eficácia atendendo à natureza e exigências das tarefas e, ainda, ao contexto ou circunstâncias em que as mesmas aparecem. O pensamento crítico e o pensamento criativo situam-se neste patamar superior de funcionamento cognitivo, abarcando as competências cognitivas de diferenciação e codificação de informação, mas sobretudo as competências de planeamento, monitorização, levantamento e comprovação de hipóteses, tomada de decisão e resolução de problemas (FACIONE, 2010; HALPERN, 2006). Lipman (1998) destaca como essas duas habilidades envolvem pensamento engenhoso e flexível, conceitualmente rico, coerentemente organizado e persistentemente exploratório. Se o pensamento crítico promove capacidades como identificar argumentos e suposições, reconhecer relacionamentos importantes, fazer inferências corretas, avaliar evidências e autoridade e tirar conclusões (FUREDY; FUREDY, 1985), a criatividade estimula o desenvolvimento da imaginação, curiosidade, resiliência, abertura a novas idéias, flexibilidade e persistência (MORAIS; FLEITH, 2017). Como se pode ver, essas são características complementares muito necessárias à adaptação individual e coletiva das pessoas face às demandas da sociedade atual, sendo importante destacar que, a par das habilidades cognitivas inerentes, estas formas superiores de pensamento requerem uma atitude sistemática ou disposição dos sujeitos para assim agirem cognitivamente (HALPERN, 2014; SAIZ; RIVAS, 2010). 
A inclusão do ensino da criatividade e do pensamento crítico nas salas de aula tem, portanto, muitas semelhanças ou proximidades que merecem ser consideradas. Ambas são competências e habilidades necessárias e que se complementam para os desafios atuais da formação, do trabalho e do progresso social e económico. Por outro lado, um ensino convencional ou magistral dessas habilidades provavelmente é incompatível com o seu desenvolvimento e aprendizado adequado. Sobretudo, ambos exigem uma metodologia e procedimentos específicos, mais assentes em competências práticas a desenvolver do que em conhecimentos teóricos a armazenar, devendo a sua apropriação e desenvolvimento assentar em oportunidades efetivas de equacionar e resolver problemas.

Nas páginas a seguir, destacamos essas semelhanças e apresentamos um conjunto de diretrizes e procedimentos didáticos específicos, que podem ser considerados eficazes para ensinar a criatividade e o pensamento crítico à distância, ou seja, nas atuais circunstâncias de pandemia que tornam impossível ou dificultam o ensino em sala de aula. Além disso, tentamos mostrar como esses procedimentos didáticos não são complexos e estão disponíveis para professores e escolas através de meios cotidianos relativamente simples.

\section{COMPLEMENTARIDADE METODOLÓGICA NO ENSINO DO PENSAMENTO CRÍTICO E DA CRIATIVIDADE}

Antes de se aprofundar em aspectos específicos do ensino, é conveniente descrever brevemente o que o pensamento crítico e a criatividade significam no nível da escola e como métodos complementares de resolução de problemas. Treffinger, Isaksen e Stead-Dorval (2006, p. 3) os definem da seguinte forma: a) Pensamento criativo: capacidade de enfrentar lacunas, paradoxos, oportunidades, mudanças ou problemas, buscando conexões significativas a partir da geração de múltiplas alternativas, possibilidades variadas (de diferentes pontos de vista ou perspectivas), alternativas incomuns ou originais e detalhes para expandir ou enriquecer as possibilidades; b) Pensamento crítico: capacidade de examinar cuidadosamente as possibilidades de maneira justa e construtiva e concentrar pensamentos e ações por meio da organização e análise de dados e idéias, redefinição e desenvolvimento de alternativas promissoras, classificação ou priorização de opções e escolha de alguns deles.

Para esses autores, gerar muitas idéias (pensamento criativo) não será suficiente por si só para ajudar a resolver um problema. Ao mesmo tempo, se confiarmos apenas no lado 
de focar a questão (pensamento crítico), teremos muito pouca escolha e, inclusive, dificuldades em nos posicionar face a problemas ainda pouco conhecidos e estruturados. Os solucionadores de problemas eficazes recorrem à complementaridade das competências cognitivas e disposicionais descritivas do pensamento criativo e do pensamento crítico, gerando opções e concentrando seu pensamento em mais de uma opção, avançando de forma criteriosa para a escolha de uma opção quando necessário (HALPERN, 2006). Para melhor concretizar essa complementaridade, Treffinger, Selby e Isaksen (2008) propõem uma caixa de ferramentas que combina técnicas para os dois modos complementares de pensar (Cf. Tabela 1).

Tabela 1: Caixa de ferramentas básica para a solução de problemas

\begin{tabular}{|l|l|}
\hline \multicolumn{1}{|c|}{ GERAR OPÇõES DE CRIATIVIDADE } & \multicolumn{1}{|c|}{ FOCAR OPÇÕES DE PENSAMENTO CRÍTICO } \\
\hline $\begin{array}{l}\text { Brainstorming e suas variações. Gerar muitas } \\
\text { opções variadas e incomuns para tarefas ou } \\
\text { perguntas abertas (as variações incluem } \\
\text { brainstorming escrito em folha de papel e com } \\
\text { notas de post-it). }\end{array}$ & $\begin{array}{l}\text { Hits and hot spots. Selecionar possibilidades } \\
\text { promissoras ou intrigantes (identificando "hits") } \\
\text { e agrupar, categorizar, organizar ou comprimir de } \\
\text { maneiras significativas (encontrando "hot } \\
\text { spots"). }\end{array}$ \\
\hline $\begin{array}{l}\text { Relações forçadas. Usar objetos ou palavras } \\
\text { que parecem não relacionadas à tarefa ou } \\
\text { problema, para criar novas possibilidades e } \\
\text { conexões. }\end{array}$ & $\begin{array}{l}\text { Refinar e desenvolver. Usar uma abordagem } \\
\text { deliberadamente construtiva para fortalecer ou } \\
\text { melhorar as opções, por exemplo considerando } \\
\text { vantagens, limitações (e maneiras de superá-las) } \\
\text { e elementos únicos. }\end{array}$ \\
\hline $\begin{array}{l}\text { Lista de atributos. Usar os elementos ou } \\
\text { atributos de uma tarefa como base para a } \\
\text { geração de novos caminhos ou introdução de } \\
\text { melhorias. }\end{array}$ & $\begin{array}{l}\text { Análise de comparação pareada. Definir } \\
\text { prioridades ou priorizar opções através de uma } \\
\text { análise sistemática de todas as combinações } \\
\text { possíveis. }\end{array}$ \\
\hline $\begin{array}{l}\text { SCAMPER. Aplicar a lista de verificação de } \\
\text { palavras ou frases de ação ("chuva de de } \\
\text { perguntas") para evocar possibilidades novas } \\
\text { ou diversas }\end{array}$ & $\begin{array}{l}\text { Sequenciamento. Organizar e focar as opções } \\
\text { com base na consideração de ações de curto, } \\
\text { médio ou longo prazo. }\end{array}$ \\
\hline $\begin{array}{l}\text { Matriz morfológica. Ferramenta analítica para } \\
\text { identificar os principais parâmetros de uma } \\
\text { tarefa, gerar possibilidades para cada } \\
\text { parâmetro e depois investigar suas } \\
\text { combinações possíveis ("misturar e e } \\
\text { combinar"). }\end{array}$ & $\begin{array}{l}\text { Matriz de avaliação. Usar critérios específicos } \\
\text { sistematicamente para avaliar cada uma das } \\
\text { várias opções ou possibilidades para orientar o } \\
\text { julgamento e selecionar opções, bem como para } \\
\text { avaliar os desempenhos conseguidos. }\end{array}$ \\
\hline
\end{tabular}

Fonte: Adaptado de Treffinger, Selby e Isaksen (2008).

Aprofundando nesta área de coincidências entre o ensino da criatividade e o pensamento crítico - e o que deve ser um bom ensino em geral - Saiz (2018) destaca, entre outros, os seguintes fatores metodológicos relevantes para o ensino do pensamento crítico: 1) aprendizagem ativa, na qual o aluno está envolvido em conteúdos dentro do seu escopo de 
compreensão, considerando logicamente a idade e a maturidade em cada caso; 2) aprendizagem baseada em problemas (ABP), ou seja, o conteúdo do ensino são situações problemáticas que podem ocorrer na vida cotidiana; 3) o interesse e a motivação do aluno, na medida em que the propomos desafios que estimulam sua curiosidade e, graças a eles, o aluno se engaja e mostra características como dedicação, investigação e observação; 4) trabalho em equipe, como elemento motivador, mas também como contraste e aprendizado com e através dos outros (aprendizado cooperativo). Essa colaboração entre os alunos também é um aspecto importante da socialização e educação para a convivência, algo muito necessário em uma sociedade que deve ser mais decisivamente orientada para a integração, a solidariedade e a racionalidade. Trata-se de aprender a ouvir e respeitar o aluno ao lado como um meio essencial para respeitar o cidadão ao lado no futuro, sobretudo quando se reconhece que os problemas complexos dos nossos dias, por exemplo o confinamento social e o controlo da propagação de um virus à escala regional, nacional e internacional, requerem a participação e a responsabilidade de todos e cada um.

Autores como López Aymes (2012), entretanto, acrescentam outros fatores relevantes na aprendizagem do pensamento crítico: 1) tarefas de escrita; 2) feedback do professor; 3) a realização de projetos; e 4) o clima da sala de aula. Em primeiro lugar, a escrita das tarefas contribui para selecionar e sintetizar idéias, reforça a estruturação de argumentos e favorece a memorização (ver, por exemplo, Bui, Myerson e Hale, 2013). Por outro lado, o feedback do professor é uma excelente maneira de expressar aceitação do aluno, reforçar o comportamento da participação na aula, esclarecer os conteúdos ou problemas que estão sendo trabalhados e orientar o novo comportamento de investigação do aluno, garantindo dinamismo à interação didática professor-aluno em sala de aula (ver, por exemplo, Lyster e Saito, 2010). Em relação à realização de projetos individuais e em grupo, é uma metodologia que estimula a aprendizagem autônoma, planejamento de tempo, autoavaliação, expressão oral e escrita e, se aplicável, a capacidade de trabalhar e aprender em equipe. Esses tipos de habilidades são muito relevantes para preparar os alunos para serem comunicadores eficientes e saber como agir cooperativamente na resolução de problemas no futuro (ver, por exemplo, Bell, 2010). Finalmente, o clima da sala de aula é um aspecto determinante do desenvolvimento da participação ativa; de fato, um ambiente em que as contribuições do aluno são valorizadas é essencial, pois a resposta do professor afeta o autoconceito escolar do aluno e, às vezes, também sua autoestima pessoal. O clima inclui aspectos como satisfação 
do aluno com a participação, preocupação dos professores com os alunos, competitividade percebida, ordem e organização das tarefas e a variedade de estímulos e técnicas utilizados pelo professor, entre outros (ver, por exemplo, Carbonero et al., 2010).

Um aspecto que podemos deduzir do exposto acima é que, frequentemente, o conteúdo e o método são combinados e sobrepostos. De fato, o "o quê" e o "como" podem coincidir na atividade didática de ensinar o pensamento crítico, pois aprender a debater para resolver um problema não apenas nos permite aprender a solução para o problema em si, mas também - e talvez mais importante em muitas ocasiões - deixa um campo de aprendizado sobre como conduzir discussões. O mesmo acontece com o ensino da criatividade, onde as técnicas usadas para resolver uma situação são mais importantes - a longo prazo - do que a própria solução. Tradicionalmente se enfatizava o saber fatual, hoje previlegia-se um saber procedimental, dando ao aluno o sentido de "agência" sobre o seu aprendizado, o seu comportamento e o seu futuro. Apenas este saber pode empoderar o aluno e futuro profissional a uma atitude mais construtiva e ativa de aprendizagem ao longo da vida, sendo fundamental que o ensino superior em particular assuma o desenvolvimento destas competências transversais nos seus currículos e práticas pedagógicas (FRANCO; ALMEIDA; SAIZ, 2014).

A partir de pesquisas sobre pensamento crítico, inúmeras propostas são feitas para o "ensino crítico" de seu conteúdo (bem como "metodologias criativas" para o ensino da criatividade). Uma peça central deste ensino é a estimulação do debate e da investigação através de perguntas que permitem aprofundar o conhecimento e a solução de problemas. Seriam todas aquelas perguntas que podem ser feitas ou ensinadas aos alunos fora das fechadas, ou seja, aquelas que seriam respondidas com um "sim" ou "não". Sem dúvida, as boas perguntas, juntamente com argumentação, observação cuidadosa de fatos e dados, inferências e deduções, detecção de vieses e falácias ou decomposição de um discurso em suas partes constituintes, são alguns dos elementos metodológicos de pensamento crítico que permitem ao aluno relacionar experiências e conhecimentos anteriores, fazer novas perguntas, levantar hipóteses e investigar ou testar a solução de problemas. A arte de perguntar aos alunos (em vez de lhes dar as respostas) também é um fator muito relevante no treinamento da criatividade, embora logicamente não atinja os níveis muito especializados que o pensamento crítico traz. Estimular tudo o que foi dito acima é importante no papel do 
professor, que se define - portanto - mais como mediador da aprendizagem do que como transmissor de conhecimento.

No entanto, não devemos esquecer que o ensino deve atender às necessidades emocionais dos alunos (FLEITH, 2016). Como apontam Virgolim, Fleith e Neves-Pereira (2009), emoções e sentimentos são o "combustível" da aprendizagem, o que motiva o sujeito a se comportar de boa vontade e com iniciativa diante dos desafios apresentados. Nesse sentido, é necessário que o professor garanta, não apenas que a comunicação didática seja dinâmica e atrativa, utilizando recursos variados como os já mencionados, mas também que a comunicação se atenha a um determinado padrão quando houver problemas de disciplina ou desinteresse por parte de alguns alunos. Nesses casos, as habilidades sociais (ver, por exemplo, Costa e López, 1996) fornecem ao professor um padrão de resposta ao aluno que Ihe permite se expressar de maneira apropriada à situação, respeitando o aluno, mas concentrando-se em resolver problemas imediatos em sala de aula e minimizar a probabilidade de problemas futuros. No ensino superior, estas preocupações devem conduzir a uma maior proximidade entre professores e estudantes pois, tradicionalmente, os modelos de ensino predominantes enfatizavam algum distanciamento relacional assumindo que os estudantes eram já adultos ou que essa proximidade poderia "infantilizar" a relação.

Em resumo, como temos verificado, quando pretendemos ensinar pensamento crítico ou criatividade, encontramos os mesmos problemas que com o ensino em geral (FERNÁNDEZ-RIVAS; SÁNCHEZ, 2019). De fato, em ambos os casos, os alunos precisam ver que o que aprenderam é útil para a vida, que possuem estratégias eficazes para assimilá-lo, que têm oportunidades de generalizá-lo para outras áreas e que podem participar ativamente de todo o processo. O aluno não é sujeito passivo no processo de ensino-aprendizagem, antes tem um papel decisivo na construção de novos conhecimentos e de competências que lhe são relevantes e Ihe fazem sentido aprender. Estas cometências e atitudes não são apenas condição necessária para boas aprendizagens nos períodos de formaçao académica, como igualmente decisivas na formação profissional e educação contínua dos indivíduos fundamentais para o exercício profissional e da cidadania em idades posteriores.

Como conclusão desta seção, na Tabela 2, resumimos alguns aspectos metodológicos que podem ser compartilhados pelo ensino-aprendizagem do pensamento crítico e da criatividade. A maioria deles pode ser aplicada ou levada em consideração para o ensino a distância, onde as exigências motivacionais, as disposições de proatividade e de 
autorreguação são ainda mais decivivas para o sucesso da formação. A tabela é expressa em termos de comportamento e experiências do aluno procurando desta forma ilustrar e estimular nos professores a visão do resultado final que pode ser alcançado quando se criam oportunidades educativas de maior participação dos alunos nos atividades curriculares.

Tabela 2: Aspectos metodológicos comuns ao ensino do pensamento crítico e da criatividade

\section{FATORES METODOLÓGICOS ASSOCIADOS AO SUCESSO (PERSPECTIVA DO ESTUDANTE)}

1. Verificar se o que aprendi é útil para minha vida cotidiana e meus interesses

2. Ser capaz de participar e ter um papel ativo na sala de aula

3. Dispor de uma variedade de técnicas e métodos de aprendizagem

4. Começar pelo meu nível de conhecimento e minha capacidade de entender

5. Aceitar desafios, sentir entusiasmo e interesse, ser motivado

6. Trabalhar em equipe, aprender com os outros e respeitar suas opiniões

7. Realizar tarefas de redação, para reforçar a seleção e retenção de idéias

8. Realizar projetos orientados a problemas

9. Realizar apresentações e debates orais, aprendendo a perguntar e pesquisar

10. Recebir feedback frequente do professor, ser guiado

11. Desfrutar de uma atmosfera de sala de aula de aceitação e ordem

12. Internalizar a convivência e abordar a resolução de conflitos a partir de um modelo de respeito e comunicação baseado em habilidades sociais (aprendizagem cooperativa)

Fonte: Elaboração própria.

Entre os programas que combinam criatividade e pensamento crítico em seu processo de solução de problemas, destaca-se a Creative Problem Solving (CPS), originalmente criado por Osborn (1957) e aperfeiçoado por Parnes (1961). É um programa que deu origem a outros de renome atual, como o International Problem Solving Program International (FPSPI) (TORRANCE; TORRANCE; WILLIAMS; HORNG, 1978) ou o Treffinger's Creative Problem-Solving Method (TCPSM) (ISAKSEN; DORVAL; TREFFINGER, 2011) e são caracterizados por combinar pensamento convergente (crítico) e divergente (criativo). O FPSPI possui seis fases: a) identificar a área de preocupação, um desafio ou problema, ainda genérico; b) selecionar o problema fundamental, específica e concretamente; c) produzir idéias ou soluções sem censura; d) gerar e selecionar critérios de decisão; e) avaliar as soluções encontradas; f) propor um plano de implementação para resolver o problema (TORRANCE; TORRANCE; CRABBE, 1983). Como podemos ver em sua descrição, exceto na etapa c) na qual idéias sem censura são produzidas (típicas do pensamento divergente), o restante das etapas anteriores e subsequentes envolve um pensamento mais racional e crítico, e a apropriação e desenvolvimento de funções cognitivas inerentes ao identificar, ponderar, selecionar e avaliar. 
Finalmente, deve-se notar que os programas de promoção da criatividade na escola possuem uma extensa bibliografia que apoia sua eficácia, mesmo havendo sempre alguma discussão sobre os critérios de avaliação a considerar na avaliação dessa eficácia (MA, 2006; PERRY, 2014; VALGEIRSDOTTIR; ONARHEIM, 2017). Os programas mais eficazes, ou seja, com maiores efeitos de treinamento a longo prazo, são aqueles que assentam em atividades e estratégias que favorecem mais a implicação pessoal e a interação dos alunos na sala de aula, têm maior duração temporal das sessões ou oportunidades de treinamento, apresentam atividades diversificadas em termos de situações, problemas ou conteúdos a trabalhar cognitivamente, e promovem a generalização do que foi aprendido na escola para as situações do cotidiano (TANG; WERNER, 2017).

Em relação ao pensamento crítico, Perkins e Grotzer (1997) fazem uma extensa revisão de iniciativas gerais de programas de instrução, como a "Filosofia para Crianças" de Lipman (LIPMAN; SHARP; OSCANYAN, 1980) ou o programa de pensamento científico (programa CASE) de Adey e Shayer (1993), com dados positivos sobre a permanência das habilidades ensinadas nos dois programas. Por outro lado, Halpern (2014) apresenta uma revisão mais atual de estudos que abordam os mecanismos específicos do pensamento crítico, todos também com resultados positivos após uma instrução. Nesse sentido, na revisão bibliográfica realizada por Willingham (2007), o autor destaca que as iniciativas mais eficazes para o ensino do pensamento crítico são as que são adaptadas a cada disciplina do currículo, com base no ensino prévio dos conhecimentos necessários para resolver o problema, que usam estratégias explícitas por meio de etapas concretas e exemplos da vida cotidiana dos alunos e que são praticadas o suficiente até seu domínio. Esta situação está de alguma forma evidenciada quando se constata que o pensamento crítico dos indivíduos aumenta com a sua maior experiência de escolarização ou educação formal pelo carater sistemático dessa mesma formação.

\section{ENSINO A DISTÂNCIA DO PENSAMENTO CRÍTICO E DA CRIATIVIDADE: A APRENDIZAGEM AUTORREGULADA}

Em um ambiente global de pandemia sanitária como o atual, é necessário valorizar todos os recursos disponíveis para aliviar as dificuldades em que o ensino presencial entrou abruptamente. Os avanços científicos e tecnológicos sem precedentes dos últimos anos 
contribuíram enormemente, com diferentes ferramentas de comunicação à distância, para o treinamento e a educação das novas gerações mais jovens. No entanto, considerando os novos desafios do futuro, é essencial incorporar uma série de habilidades e capacidades que permitam que os indivíduos aprendam a distância.

O ensino a distância possui características distintas que precisam ser incorporadas às metodologias de ensino. Com efeito, quando o ensino em sala de aula desaparece total ou parcialmente, o professor precisa de novos recursos que estimulem a motivação e a dedicação do aluno. Nesse contexto, podemos considerar a chamada "aprendizagem autorregulada" como uma ferramenta valiosa para apoiar a aprendizagem autônoma que caracteriza grande parte do ensino a distância. Nesse sentido, o relatório da Associação Americana de Psicologia (AMERICAN PSYCHOLOGICAL ASSOCIATION, 2017) sobre as 20 chaves para futuras reformas da educação é muito revelador, destacando que a autorregulação dos estudantes não é apenas um fator decisivo para se aprender em uma sociedade avançada, mas também que essa habilidade pode ser ensinada, de modo que isso abre uma excelente maneira de estimular a iniciativa dos alunos por parte dos professores.

A aprendizagem autorregulada (self-regulated learning) é um modelo de aprendizagem que tem suas raízes em abordagens sociocognitivas (ZIMMERMAN, 2008) e destaca a importância da iniciativa e atividade do aluno e sua capacidade de regular seu comportamento nos âmbitos cognitivo, motivacional e contextual (PANADERO; ALONSOTAPIA, 2014). A autorregulação pode ser aprendida de forma intencional e progressiva, através de exercícios adaptados a diferentes idades. Em geral, o processo de ensino da autorregulação considera dois aspectos essenciais: as habilidades e a vontade ou motivação do aluno (MCCOMBS; MARZANO, 1990). Ambos se complementam, pois não basta ensinar estratégias metacognitivas aos alunos para organizar e gerenciar suas competências, mas também é necessário enfatizar sua motivação para aprender e organizar o ambiente e as atividades de treinamento. Este aspeto destaca, de novo, o papel do pensamento crítico e criativo enquanto duas formas complementares de organizar a cognição, o ato de conhecer e de aprender, as atitudes ativas de enfrentar e resolver problemas. Aliás, também ao nível do próprio pensamento crítico e criativo, a par das habilidades cognitivas subjacentes a estes estilos ou formas cognitivas de atuar, importa a componente motivacional como predisposição e atitude regular do sujeito de agir cognitivamente segundo essas formas mais 
elaboradas e sistemáticas, também necessariamente mais custosas, de pensamento (ALMEIDA; FRANCO, 2011; SAIZ; RIVAS, 2010).

Entre as estratégias de ensino de autorregulação, vale destacar (TORRANO; FUENTES; SORIA, 2017): 1) Ensino direto, no qual o professor ensina diretamente o aluno a gerenciar informações, quando e como usar diferentes metodologias e quais procedimentos motivacionais estão disponíveis para eles; 2) Prática orientada e autônoma, cujo objetivo é transferir progressivamente a responsabilidade e o controle do processo de aprendizagem. Por exemplo, no chamado "ensino recíproco", os alunos atuam primeiro como alunos e depois como professores que ensinam seus colegas de classe ou na chamada "sala de aula invertida", o professor atua como um guia para o trabalho colaborativo dos alunos; 3) Modelagem, baseada no potencial de imitar o professor ou outro estudante especialista; 4) Autoobservação, que é a conscientização das dificuldades e os meios para resolvê-las; e 5) A prática autorreflexiva, na qual o aluno avalia seu desempenho e é capaz de ajustar seu comportamento e ambiente para otimizar o resultado.

Alguns professores podem pensar que incorporar a autorregulação em seu ensino é uma tarefa nova e impossível, acrescentando ainda mais toda a responsabilidade e demanda que o confinamento colocou em suas costas. Mas não se trata de fornecer idéias inviáveis ou que exijam meios além do alcance do professor da sala de aula, mas de oferecer pistas simples que podem ser incorporadas sem muitas complicações à situação diária do ensino a distância, por exemplo:

1. Tornar a tarefa mais significativa para o aluno, em relação à sua vida real e cotidiana. Por exemplo, podemos tornar a matemática mais interessante começando com figuras geométricas na areia, como Arquimedes? Quanto mais interessante a tarefa, menor a motivação externa que teremos que incorporar. Além das experiências interessantes que podemos oferecer, devemos garantir que as tarefas sejam variadas e adaptadas a cada assunto, aliás aproveitando muitos dos problemas e desafios que encontramos no nosso cuotidiano.

2. Ajudar a criar um ambiente de aprendizagem em casa que evite distrações internas e ambientais e favoreça a gestão das emoções e o controle da impulsividade. Por exemplo, podemos pedir a cada aluno que faça uma lista de coisas ou atividades que os distraem? Algumas podem ser excluídas, outras 
podem ser adiadas para mais tarde e outras podem servir como prêmios ou ser regulamentadas pelos pais. Cada criança pode ter um horário semanal de organização das suas atividades ou fazer um registro do tempo em que permanece trabalhando, para que possamos usar a média desse tempo para medir os intervalos de trabalho, os prêmios e jogos e os descansos. Em tudo isso, podemos solicitar a colaboração dos pais.

3. Oferecer ao aluno tarefas que incluam algum grau de auto-planejamento e auto-avaliação de sua aprendizagem. Por exemplo, podemos the dar os passos de uma atividade bagunçados, para ele fazer tentativas e desenvolver a autoobservação? Também pode-se estimular o diálogo interno (com as crianças mais novas, primeiro o diálogo externo) e a experiência de detecção de erros como uma "caça ao tesouro", com alguma ênfase no carater lúdico e interessante que podem ter as aprendizagens.

4. Apresentar ao aluno procedimentos de trabalho que sugiram várias maneiras de fazer algo, de buscar informações, de estabelecer conexões entre algumas idéias e outras, de desenvolver produtos como diagramas, mapas mentais, simulações, cadernos de campo, modelos e artefatos... Será importante, nesta forma de trabalho, estabelecer estágios ou fases, para que o aluno encontre seu reforço de tempos em tempos e a tarefa não seja esmagadora.

5. Finalmente, trabalhar remotamente não significa que não exista relação entre os próprios alunos. Portanto, ocasionalmente, será interessante incluir tarefas ou projetos para os quais eles devem entrar em contato, em grupos de trabalho cooperativos heterogêneos e flexíveis.

Frequentemente, o problema da educação a distância que promove a autoregulação pode ser mais uma questão de adaptação às circunstâncias e proximidade emocional. De fato, como aponta a teoria da autodeterminação de Deci e Ryan (2002), é necessário não apenas estruturar o contexto para que o aluno seja autônomo, mas também levar em consideração as necessidades de competência e conexão emocional dos alunos, para promover o seu sentido de agência, a auto-motivação e a aprendizagem autorregulada. Então, sabemos como nos conectar e comunicar com nossos alunos? Nesse sentido, pode ser muito útil conhecer algumas técnicas de tutoria, como simplesmente iniciar a comunicação com o 
aluno perguntando sobre seu dia, sua situação, suas atividades, etc., então podemos resolver suas dificuldades e preocupações com as tarefas e, finalmente, faremos as solicitações mais difíceis, relacionadas ao esforço e dedicação às aprendizagens formais a realizar.

\section{CONSIDERAÇÕES FINAIS}

Se tivéssemos que destacar quais condições ou características podem estar mais associadas ao sucesso da criatividade e das metodologias de ensino do pensamento crítico, talvez apontássemos dois eixos: a) a alternância do pensamento convergente com o pensamento divergente na análise de situações e resolução de problemas; e b) a combinação de atividades intelectuais e cognitivas com outras que têm um fundo basicamente emocional e motivador.

A alternância de pensamento convergente e divergente permite que os alunos deem um salto qualitativo na análise e compreensão de situações. Com o pensamento divergente ou criativo, as opções e formas de trabalho são abertas e, com o pensamento convergente, mais crítico e racional, as melhores opções são selecionadas e os resultados alcançados serão avaliados em termos da sua eficiência e resoluções conseguidas. Como aponta Beghetto (2016), esses processos de pensamento divergente e convergente permitem a reestruturação da realidade através de novas experiências baseadas em conhecimentos prévios e, sobretudo, um processo contínuo e integral de construção de conhecimentos e de competências (saber aprender, saber fazer, saber ser e estar com os outros para nos reportarmos ao relatório da UNESCO sobre os objetivos da educação).

Por seu lado, as emoções desempenham um papel vital na criatividade e no pensamento crítico (VAN DE VLIERT; MURRAY, 2018) porque, através da expressão de sentimentos e desejos, os alunos participam intensamente na realização de atividades, promovendo o surgimento de habilidades cognitivas. Em outras palavras, um maior envolvimento emocional dos alunos nas tarefas pode fazer emergir suas habilidades criativas na solução de problemas (KAUFMAN, 2015), principalmente em contextos de ensino a distância, que (i) obrigam o professor a incorporar novos recursos pedagógicos e de comunicação efetiva, e (ii) obrigam o aluno ao exercício de maior autorregulação emocional e cognitiva, automotivação e autonomia em geral. 
Desta forma, é fundamental fornecer conhecimentos úteis e desenvolver competências práticas que favoreçam a auto-regulação da aprendizagem, em contextos de ensino a distância e com meios simples, disponíveis para qualquer professor. É verdade que existem estudantes que não têm os meios técnicos para trabalhar remotamente ou vivem em situações vulneráveis e não recebem o apoio necessário da família ou da comunidade. Para evitar isso, as instituições de ensino devem reagir rapidamente, tanto com recursos materiais que promovam o acesso de todos os alunos ao ensino quanto com ações de treinamento que permitam a máxima eficácia do sistema educacional na situação atual. Sem uma atenção a estes aspetos, as dificuldades de ensino-aprendizagem criadas pela atual pandemia podem estar a reforçar diferenças e estratificações sociais que o movimento dos direitos cívicos e de democratização do acesso e sucesso educativo procurava atenuar nas últimas décadas

Em suma, a escola precisa urgentemente de fórmulas eficazes para incorporar nas suas atividades formativas as competências transversais ou habilidades que a sociedade exige (GLAVEANU, 2018). A visão da criatividade e do pensamento crítico como atividades isoladas ou fora do currículo escolar não parece compatível com a necessidade de empreendedores que desafiem maneiras convencionais de pensar e fazer as coisas numa sociedade em permanente e profunda mudança (FLEITH, 2016). Como Fernández-Rivas e Sanchez (2019) apontam, a capacidade de pensar de forma crítica e criativa é mais importante do que nunca para alcançar um mínimo de bem-estar pessoal e treinamento profissional adequado para enfrentar os desafios da sociedade atual, desde logo o desafio de processar eficazmente o volume abundante de informação que temos disponível ou que a publicidade nos faz chegar. Os processos de ensino, de aprendizagem e de avaliação não se podem justificar por si mesmos antes devem estar ao serviço da apropriação e desenvolvimento sistemático de competências curriculares e transversais por parte dos alunos que sirvam as necessidades pessoais e sociais e atendam à complexidade dos desafios dos nossos dias.

\section{REFERÊNCIAS}

ADEY, P.; SHAYER, M. An exploration of long-term far-transfer effects following an extended intervention program in the high school science curriculum. In: Cognition and instruction, v. 11, n. 1, p. 1-29, 1993.

ALMEIDA, L. S., \& FRANCO, A. Critical thinking: Its relevance for education in a shifting society. Revista de Psicología, v.29, n.1, p.175-195, 2011. 
AMERICAN PSYCHOLOGICAL ASSOCIATION. Center for Psychology in Schools and Education. Top 20 principles from psychology for preK-12 creative, talented, and gifted students' teaching and learning. 2015. Disponível em: http://www.apa.org/ed/schools/teachinglearning/top-twenty-principles.aspx. Acesso em: 22 abr. 2020.

BEGHETTO, R. A. Creative openings in the social interactions of teaching. In: Creativity: Theories-Research-Applications, v. 3, n. 2, p. 261-273, 2016.

BELL, S. Project-based learning for the 21st century: Skills for the future. In: The Clearing House, v. 83, n. 2, p. 39-43, 2010.

BUI, D. C.; MYERSON, J.; HALE, S. Note-taking with computers: exploring alternative strategies for improved recall. In: Journal of Educational Psychology, v. 105, n. 2, p. 299-309, 2013.

CARBONERO, M. Á.; MARTÍN-ANTÓN, L. J.; ROMÁN, J. M.; REOYO, N. Efecto de un programa de entrenamiento al profesorado en la motivación, clima de aula y estrategias de aprendizaje de su alumnado. In: Revista Iberoamericana de Psicología y Salud, v. 1, n. 2, p. 117-138, 2010.

COSTA, M.; LÓPEZ. E. Manual para el educador social 2: afrontando situaciones. Madrid: Ministerios de Asuntos Sociales, 1996.

DECI, E. L.; RYAN, R. M. Overview of self-determination theory: an organismic dialectical perspective. In: Handbook of self-determination research. New York: University of Rochester Press, 2002, p. 3-33.

FACIONE, P. A. Critical thinking: What it is and why it counts. Insight assessment.2010 Disponivel em: http://www.insightassessment.com/home.html. Acesso em: 17 de jun. 2020.

FERNÁNDEZ-RIVAS, S.; SÁNCHEZ, C. S. La necesidad de la evaluación del pensamiento crítico en la enseñanza superior. In: FORO INTERNACIONAL SOBRE LA EVALUACIÓN DE LA CALIDAD DE LA INVESTIGACIÓN Y LA EDUCACIÓN SUPERIOR - FECIES, XVI, 2019, Santiago de Compostela. Libro de actas [...]. Murcia: Asociación Española de Psicología Conductual AEPC, 2019.

FLEITH, D. S.; BRAGA, N. P. Criatividade no ensino superior. In: ALMEIDA, L. S. Estudantes do Ensino Superior: desafios e oportunidades. Braga-Portugal: ADIPSIEDUC Associação para o Desenvolvimento da Investigação em Psicologia da Educação, 2019. p. 215-232.

FLEITH, D. S. Creativity, motivation to learn, family environment and giftedness: A comparative study. In: Psicologia: Teoria e Pesquisa, n. 32, p. 1-9, 2016.

FRANCO, A. R, ALMEIDA, L. S.; SAIZ, C. Pensamiento crítico: Reflexión sobre su lugar en la Enseñanza Superior. Educatio Siglo XXI, v.32, p.2., p. 81-96, 2014.

FUREDY, C.; FUREDY, J. J. Critical Thinking: Toward Research and Dialogue. In: New directions for teaching and learning, n. 23, p. 51-69, set/1985. 
GLAVEANU, V. P. Perspective Collective Futures: Creativity and Imagination in Society. In: SAINT-LAURENT, C.; OBRADOVIC, S.; CARRIERE, K. (eds.). Imagining Collective Futures: Palgrave studies in creativity and culture. Cham: Palgrave Macmillan, 2018. p. 83-105.

HALPERN, D. F. (2006). The nature and nurture of critical thinking. In: STERNBERG, R. J.; ROEDIGER, H.L.; D. F. HALPERN, D.F. (eds.), Critical thinking in psychology . Cambridge, UK: Cambridge University Press. 2006. p. 1-14.

HALPERN, D. F. Critical Thinking Across the Curriculum: A Brief Edition of Thought \& Knowledge. London: Routledge, 2014.

ISAKSEN, S. G.; DORVAL, K. B.; TREFFINGER, D. J. Creative approaches to problem solving: A framework for innovation and change. 3. ed. London: Sage Publications, 2011.

KAUFMAN, J. C. Creativity is life: a comment on the special number. In: Journal of Creative Behavior, v. 49, n. 3, p. 233-237, 2015.

LAITON, I. P. Modelo de enseñanza de pensamiento crítico. In: Cuadernos ETITC. BogotáColômbia: Escuela Tecnológica Instituto Técnico Central, maio/2019. Disponível em: http://repositorio.itc.edu.co/handle/001/407. Acesso em: 17 jun. 2020.

LIPMAN, M. Teaching students to think reasonably: Some findings of the Philosophy for Children program. In: The Clearing House, Washington, v. 71, n. 5, p. 277-280, 1998.

LIPMAN, M.; SHARP, A. M.; OSCANYAN, F. Philosophy in the classroom. Philadelphia: Temple University Press, 1980

LÓPEZ, G. A. Pensamiento crítico en el aula. In: Docencia e investigación: Año XXXVII. Ciudad Real-Espanha: Universidad de Castilla La Mancha, 2a época, n. 22, jan/dez 2012.

LYSTER, R.; SAITO, K. Oral feedback in classroom SLA: a meta-analysis. In: Studies in second language acquisition, 2010, p. 265-302.

MA, H. A synthetic analysis of the effectiveness of single components and packages in creativity training programs. In: Creativity Research Journal, 18 (4), p. 435-446, 2006.

MCCOMBS, B. L.; MARZANO, R. J. Putting the self in self-regulated learning: the self as agent in integrating will and skill. In: Educational psychologist, v. 25, n. 1, p. 51-69, 1990.

MORAIS, M. F.; FLEITH, D. S. Conceito e avaliação da criatividade. In: ALMEIDA, L. S. Criatividade e pensamento crítico: conceito, avaliação e desenvolvimento. Braga-Portugal: CERPSI Centro de Estudos e Recursos em Psicologia, 2017. p. 19-44.

OCDE/CAF/CEPAL. Perspectivas económicas de América Latina 2018: repensando las instituciones para el desarrollo. Paris: Éditions OCDE, 2018. Disponível em: http://dx.doi.org/10.1787/leo-2018-es. Acesso em: 20 mai. 2020.

OSBORN, A. F. Applied imagination. 1. ed. New York: Scribner, 1957. 
PANADERO, E.; ALONSO-TAPIA, J. Teorías de autorregulación educativa: una comparación y reflexión teórica. In: Psicología Educativa, v. 20, n. 1, p. 11-22, 2014.

PARNES, S. J. Effects of extended effort in creative problem solving. In: Journal of Educational psychology, Washington, v. 52, n. 3, p. 117-122, 1961.

PERKINS, D. N.; GROTZER, T. A. Teaching intelligence. In: American Psychologist, v. 52, n. 10, p. 1125-1133, 1997.

PERRY, A. Creativity and its antecedents: an investigation of different assessments and training effects. 176 p. Tese (Doutorado em 2014) - lowa State University, Amis, 2014.

SAIZ, C. Pensamiento crítico y eficacia. Madrid: Pirámide, 2018.

SAIZ, C.; RIVAS, S. F. Pensamiento crítico y bienestar como prevención del abandono de los estudios. In: BERNARDO, A. B.; TUERO, E.; ALMEIDA, L. S.; NUÑEZ, J. C. (eds.). Motivos y factores explicativos del abandono de los estudios: claves y estrategias para superarlo. Madrid-Espanha: Pirámide, 2020. p. 201-219.

SAIZ, C.; RIVAS, S. F. (2010). Mejorar el pensamiento crítico contribuye al desarrollo personal de los jóvenes? In: RIBEIRO, H. J.; VICENTE, J. N.(eds.), 0 lugar da lógica e da argumentação no ensino da Filosofia. Universidade de Coimbra: Unidade I \& D, Linguagem, Interpretação e Filosofia. 2020. p. 39-52.

TANG, M.; WERNER, C. H. An interdisciplinary and intercultural approach to creativity and innovation: Evaluation of the EMCI ERASMUS intensive program. In: Thinking Skills and Creativity, 2017, v. 24, p. 268-278.

TORRANCE, E. P. Can we teach children to think creatively? In: Journal of Creative Behavior, v. 6, n. 2, p. 114-143, 1972.

TORRANCE, E. P.; TORRANCE, L. P.; WILLIAMS, S. J.; HORNG, R. Y. Handbook for training future problem solving. Athens: University of Georgia, 1978.

TORRANCE, J. P.; TORRANCE, E. P; CRABBE, A. Handbook for training FPS teams: 1983. Cedar Rapids: Future Problem Solving Program/Coe College, 1983.

TORRANO, F.; FUENTES, J. L.; SORIA, M. Aprendizaje autorregulado: estado de la cuestión y retos psicopedagógicos. In: Perfiles Educativos, v. 39, n. 156, p. 160-173, 2017.

TREFFINGER, D. J.; ISAKSEN, S. G.; DORVAL, K. B. Creative problem solving: an introduction. 4. ed. Waco-Texas: Prufrock Press, 2005.

TREFFINGER, D. J.; SELBY, E. C.; ISAKSEN, S. G. Understanding individual problem-solving style: a key to learning and applying creative problem solving. In: Learning and Individual Differences, v. 18, n. 4, p. 390-401, 2008. 
VALGEIRSDOTTIR, D.; ONARHEIM, B. Studying creativity training programs: a methodological analysis. In: Creativity and Innovation Management, v. 26, n. 4, p. 430-439, 2017.

VAN DE VLIERT, E.; MURRAY, D. R. Climate and creativity: cold and heat trigger invention and innovation in richer populations. In: Creativity Research Journal, 2018, v. 30, n. 1, p. 17-28, 2018.

VIRGOliM, A. M.; FLEITH, D. S.; PEREIRA, M. S. Toc, Toc, Plim, Plim: lidando com as emoções, brincando com o pensamento através da criatividade. Campinas: Papirus. 2009.

WILLINGHAM, D. T. Critical thinking: why it is so hard to teach? In: American federation of teachers summer 2007, p. 8-19, 2007.

WORLD ECONOMIC FORUM. The Future of Jobs: employment, skills and workforce strategy for the fourth industrial revolution. Jan./2016. Disponível em:

http://www3.weforum.org/docs/WEF_Future_of_Jobs.pdf. Acesso em: 20 abr. 2020.

ZIMMERMAN, B. J. Investigating self-regulation and motivation: historical background, methodological developments and future prospects. In: American Educational Research Journal, v. 45, n. 1, p. 166-183, 2008.

\section{Revisão gramatical por: Thatiane Bezerra Teixeira de Oliveira}

E-mail: thatiane.oliveira@ufpe.br

RECEBIDO 14 DE SETEMBRO DE 2020.

APROVADO 30 DE OUTUBRO DE 2020. 